\title{
Analisis Pengeringan Kopi Menggunakan Oven Pengering Hybrid (Solar Thermal Dan Biomassa) Di Desa Gununghalu
}

\author{
Yefri Chan $^{1}$, Didik Sugiyanto ${ }^{2 *}$, Aep Saepul Uyun ${ }^{3}$ \\ ${ }^{1,2}$,Teknik Mesin Universitas Darma Persada \\ ${ }^{3}$ Pascasarjana Energi Terbarukan Universitas Darma Persada \\ Email ; yefrichan@ft.unsada.ac.id ; didik_sugiyanto@ft.unsada.ac.id, aepsuyun@pasca.unsada.ac.id \\ *Corresponding author - Email : didik_sugiyanto@ft.unsada.ac.id
}

Artkel Info - : Received : 20 Dec 2019; Revised : 12 Feb 2020; Accepted: 20 Feb 2020

\begin{abstract}
Salah satu proses dalam pengolahan biji kopi menjadi bubuk kopi adalah pengeringan biji kopi yang dapat dilakukan secara natural maupun biji kopi yang sudah dikupas kulit luarnya (honey), proses pengeringan yang umum digunakan adalah pengeringan matahari langsung, proses ini bisa membutuhkan waktu lama dan terkendala dengan tingkat curah hujan yang tinggi terutama didaerah dataran tinggi seperti di desa Gununghalu, Dusun Tangsi Jaya, Kabupaten Bandung Barat. Untuk menjawab permasalahan ini maka dibuatlah mesin pengering Hybrid (Solar thermal dan biomassa).

Mesin Pengering Hybrid untuk kopi ini memanfaatkan cahaya matahari dan pembakaran dari kayu atau ampas kopi sebagai bahan bakarnya, ukuran dari oven pengering hybrid ini adalah panjang 8m, lebar $3 \mathrm{~m}$ dan tinggi 2,4 $\mathrm{m}$, tungku biomassa dengan dimensi panjang 1,2 $\mathrm{m}$, lebar 1,2 $\mathrm{m}$ dan tinggi 1,3 m, kapasitas pengeringan $800 \mathrm{~kg}$ sekali proses. Dari hasil pengujian didapatkan lama pengeringan kopi untuk proses natural selama 7 hari dan untuk proses honey selama 4 hari, suhu tertinggi dalam ruangan 51,9 oC, proses pengeringan ini lebih cepat 2 hari dibandingkan dengan pengeringan matahari langsung dan hasil pengeringan lebih higeinis
\end{abstract}

Kata kunci: Mesin pengering hybrid, Kopi, Biomassa, Suhu.

\section{Abstract}

One of the processes of in tillage a seed of the coffee into a powder coffee is the drying up of a seed of the coffee that can be been carried out to the natural as well as a seed of the coffee that had already been is pared a skin (hone), process of drying the common otter of euro used of these tests are the drying up of the sun directly, the process can be taken a long time and is hindered by the rain precipitation who high especially investation in the highlands of such as gununghalu village, Dusun Tangsi Jaya, West Bandung Regency .To answer this problem so government has built the the hybrid drying machine (thermal solar and biomass ).

Hybrid drying machine for coffee utilizes sunlight and combustion as of wood or coffee grounds as fuel, , dimension from the oven dryer hybrid is long $8 \mathrm{~m}$, wide 2,4 $\mathrm{m}$ and high 2,4 $\mathrm{m}$ the biomass as to dimensions long 1,2, $\mathrm{m}$ wide 1,2 $\mathrm{m}$ and high 1,3, $\mathrm{m}$ the drying process $800 \mathrm{~kg}$ once. From the testing or old drying coffee to the process of natural during 7 day and to the process of honey during 4 day, the highest temperature in the dryer $51,9 \circ \mathrm{o}$, process of drying is faster than by drying 2 day the sun more directly and the drying higeinis.

Keywords: Hybrid drying machine, coffee, biomass, temperature.

\section{PENDAHULUAN}

Desa Gununghalu Kecamatan Gununghalu di Kabupaten Bandung Barat. Secara administratif Dusun Tangsi Jaya terletak di Desa Gununghalu, Kecamatan 
Gununghalu, Kabupaten Bandung Barat. Dusun yang hanya terdiri tak lebih dari 100 kepala keluarga dengan rumah-rumah yang tersebar terletak di kaki Pegunungan Kendeng, pegunungan dengan hutan menghijau yang masih lebat dan alami, sungai utama Cidadap mengalir sepanjang musim.( A.S. Uyun dkk, 2011)

Dusun Tangsi Jaya mempunyai unit pengolahan kopi berbasis energi terbarukan dimana sumber listriknya berasal dari Pembangkit Listrik Tenaga Mikro Hidro (PLTMH), unit pengolahan kopi ini merupakan hibah dari Mitsui. Co Jepang dan Universitas Darma Persada, saat ini unit pengolahan kopi dapat berfungsi dengan baik. Salah satu kendala yang dihadapi pengelola koperasi dan petani kopi adalah belum tersedianya mesin pengering untuk mengeringkan kopi setelah di panen dan setelah proses pengelupasan kulit. Karena curah hujan yang tinggi kebutuhan akan mesin pengering ini sangat dibutuhkan.

Mesin pengering hybrid dengan memanfaatkan panas matahari dan panas hasil pembakaran tungku biomassa merupakan solusi untuk menjawab permasalahan diatas, anggaran untuk membuat mesin pengering ini didapat melalui skema hibah Teknologi Tepat Guna (TTG) dari DIKTI.

\section{TINJAUAN PUSTAKA}

Pengeringan dengan metode penjemuran langsung mempunyai banyak kelemahan seperti kurang higienis, memerlukan tenaga kerja yang lebih intensif, area yang luas (Jyoti, S \& Pankaj, 2015).Pengeringan merupakan cara pengawetan makanan dengan biaya rendah. Tujuan pengeringan adalah menghilangkan air, mencegah fermentasi atau pertumbuhan jamur dan memperlambat perubahan kimia pada makanan. Selama pengeringan dua proses terjadi secara simultan yaitu perpindahan panas ke produk dari sumber pemanas dan perpindahan massa uap air dari bagian dalam produk ke permukaan dan dari permukaan ke udara sekitar. (Gunasekaran dkk, 2012).

Penambahan tungku pembakaran biomassa dan pemberian sirkulasi udara(inlet dan outlet) cukup memungkinkan alat pengering bisa bekerja optimal dengan energi kombinasi dari energi surya dan biomassa tempurung kelapa. Energi panas dari biomassa ini dihantarkan oleh kipas ke dalam ruang pengering, sehingga terjadinya pergerakan laju aliran udara di dalam alat. Penggunaan bahan baku tempurung kelapa untuk prosespembakaran dikarenakan nilai kalor tempurung kelapa lebih besar dibandingkan dengan bahan baku lain seperti tongkol jagung, sekam padi, serbuk gergaji dan cangkang sawit (Nuriana dkk, 2013).

Biomassa merupakan bahan-bahan organik berumur relatif muda dan berasal dari

tumbuhan, hewan, produk dan limbah industri budidaya (pertanian, perkebunan, kehutanan,

peternakan, perikanan). Unsur utama dari biomassa adalah bermacam-macam zat kimia

(molekul) yang sebagian besar mengandung atom karbon (C) (Supriyanto dan Merry, 2010).

Pengeringan kopi sebaiknya dilakukan pada temperatur antara 50 sampai $55 \mathrm{C}$, karena pada temperatur ini perpindahan partikel air dan penguapannya berlangsung dengan baik. Temperatur pengeringan yang terlalu tinggi dapat menyebabkan terjadinya kerusakan permukaan biji (case hardening), perpindahan partikel air di dalam biji menjadi sulit dan berakibat pada penurunan mutu biji kopi yang dikeringkan (Widyotomo dkk. 2005)

Kadar air yang terkandung dalam produk dinyatakan dalam dua cara, yaitu basis basah dan basis kering. Kadar air basis basah dapat didefinisikan sebagai perbandingan massa air pada produk dengan massa total produk. Secara matematika kadar air basis basah ditulis sebagai berikut : 


$$
M C_{w b}=\frac{M_{o}-M_{d}}{M_{o}} \quad \text { Pers } 1
$$

sedangkan kadar air basis kering adalah massa air pada produk persatuan massa kering produk, dinyatakan dengan Persamaan 2.

$$
M C_{d b}=\frac{M_{o}-M_{d}}{M_{d}} \quad \text { Pers } 2
$$

dimana:

MCwb adalah kadar air basis basah MCdb adalah kadar air basis kering Mo adalah massa total produk Md adalah massa produk tanpa air

Sedangkan laju pengeringan dihitung dengan menggunakan persamaan 3 .

Laju pengeringan $=\frac{m_{\text {awal }}-m}{m_{\text {akhir }}} \quad$ Pers 3

dimana:

mawal adalah massa produk mula-mula makhir adalah massa akhir produk (kering) $\mathrm{t}$ adalah waktu pengeringan

Untuk memperoleh kualitas pengeringan yang bagus, ada beberapa parameter yang harus dikontrol selama proses pengeringan, yaitu kecepatan aliran udara, temperatur udara pengering dan kelembaban relatif udara

\section{METODE}

Penelitian ini dilaksanakan pada bulan Juni sampai dengan bulan Desember 2019, di Dusun Tangsi Jaya. Desa Gununghalu. Untuk fabrikasi dari mesin pengering hybrid dilakukan di Workshop CV. Laskar Teknik Kota Bekasi.

\subsection{Mesin Pengering Hybrid}

Mesin pengering hybrid yang dibuat mempunyai dimensi panjang $8 \mathrm{~m}$, lebar 3 $\mathrm{m}$ dan tinggi $2,4 \mathrm{~m}$, didalam mesin pengering terdapat 4 buah rak berukuran panjang 5,9 $\mathrm{m}$ dan lebar $1,15 \mathrm{~m}$. Tungku biomassa ukuran panjang $1,2 \mathrm{~m}$, lebar 1,2 $\mathrm{m}$ dan tinggi $1,3 \mathrm{~m}$. Mesin pengering hybrid ini dilengkapi dengan kontrol otomatis untuk kelembaban dan temperatur udara.

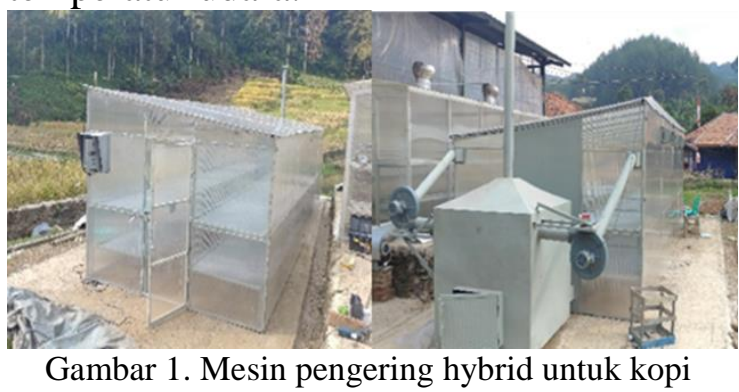

\subsection{Bahan Uji}

Bahan uji yang digunakan untuk pengujian mesin pengering hybrid adalah, kopi jenis Robusta dengan cara pengeringan natural dan cara pengeringan dimana kulit bagian luar sudah di kelupas (honey)

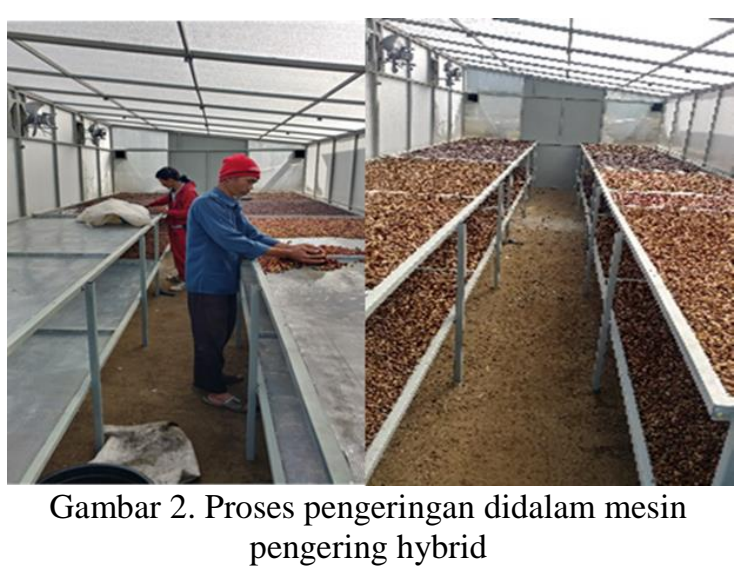

\subsection{Prosedur Pengujian}

Pengujian mesin pengering hybrid dilakukan dengan 2 cara yaitu, cara pertama pengujian dengan sumber energi panas hanya dari matahari saja, cara yang kedua pengujian dengan sumber energi panas dari tungku biomassa saja ini dilakukan pada sore sampai malam hari. Jumlah bahan uji secara keseluruhan adalah $800 \mathrm{~kg}$, terdiri dari $500 \mathrm{~kg}$ bahan kopi pengolahan honey dan $300 \mathrm{~kg}$ pengolahan secara natural. 


\section{HASIL DAN PEMBAHASAN}

1. Pengujian dengan sumber energi panas dari matahari

Suhu pada ruang pengering saat pengujian berkisar antara $36,8^{\circ} \mathrm{C}$ sampai $51,9^{\circ} \mathrm{C}$ dengan nilai rata-rata $43,6^{\circ} \mathrm{C}$, intensitas matahari tertinggi sebesar $990 \mathrm{~W} / \mathrm{m}^{2}$. Sementara suhu lingkungan pada pada saat itu berkisar antara $23,5^{\circ} \mathrm{C}$ sampai $34,5^{\circ} \mathrm{C}$. Hal ini membuat alat pengering hybrid bekerja dengan efektif dikarenakan temperatur ruang pengering lebih tinggi dibandingkan dengan temperatur lingkungan.



Gambar 3. Suhu dalam ruang pengering dan intensitas matahari

Dari gambar 3 diatas dapat terlihat perubahan suhu ruangan sebanding dengan kenaikkan intensitas matahari, kondisi cuaca yang tidak menentu kadang-kadang berawan secara tiba-tiba juga turut mempengeruhi turun naiknya suhu ruangan.

2. Pengujian dengan sumber energi panas dari tungku biomassa

Pengujian dengan tungku biomassa dilakukan pada sore sampai malam hari, untuk biomassa yang digunakan berupa kayu balok, ranting pohon dan bambu yang sudah kering, jumlah biomassa yang digunakan sebanyak $5 \mathrm{~kg} / \mathrm{jam}$. Suhu ruang dengan pemanasan menggunakan biomassa adalah $31,3{ }^{\circ} \mathrm{C}$ sampai $41,1{ }^{\circ} \mathrm{C}$ dengan rata-rata $35,8{ }^{\circ} \mathrm{C}$, dengan suhu lingkungan berkisar antara 20,3 oC sampai 25,1 oC, untuk suhu luaran dari tungku biomassa antara $51{ }^{\circ} \mathrm{C}$ sampai 97,1

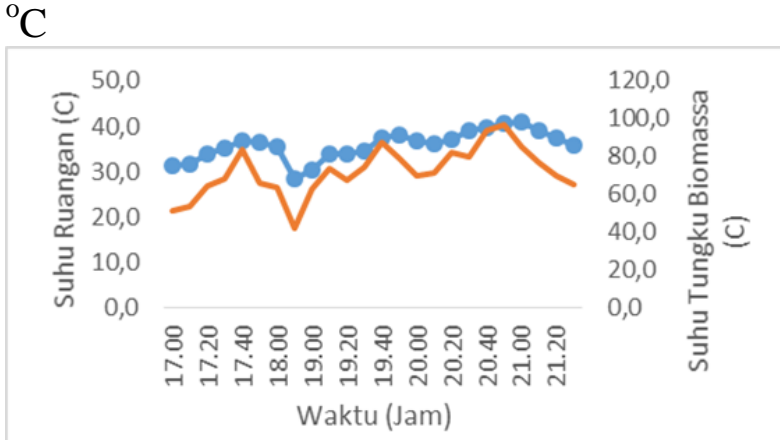

Gambar 4. Suhu dalam ruang pengering dan suhu tungku biomassa

Grafik yang ditunjukkan gambar 4 diatas dapat terlihat perubahan suhu ruangan sebanding dengan kenaikkan dan penurunan dari suhu yang dihasilkan oleh tungku biomassa, perubahan suhu biomassa lebih banyak dipengaruhi oleh suplai bahan bakar yang tidak konstan.

\section{Penurunan kadar air kopi}

Kadar air awal bahan untuk kopi robusta sekitar $65 \%$, selama proses pengeringan penurunan rata-rata kadar air bahan tiap jam sebesar 2,1\%.

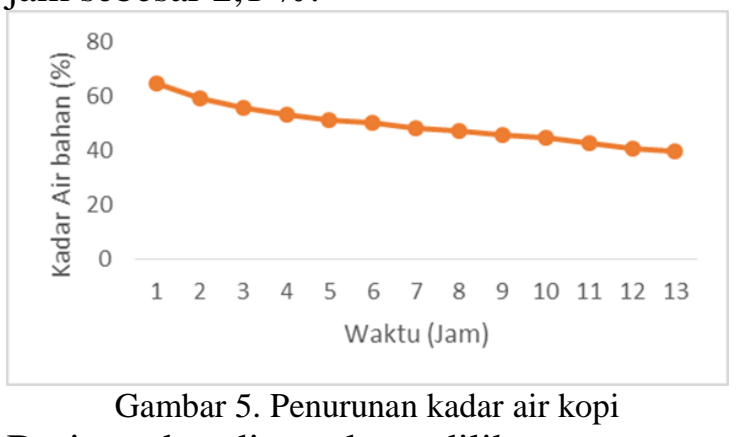

Dari gambar diatas dapat dilihat persentase penurunan kadar diawal lebih besar dan semakin lama persentasenya semakin kecil, ini biasa dalam proses pengeringan karena diawal pengeringan bahan masih dalam kondisi basah, dan bahan lebih cepat untuk melepaskan uap air ke udara.

\section{KESIMPULAN}

Mesin pengering hybrid untuk kopi mempunyai dimensi panjang $8 \mathrm{~m}$, lebar $3 \mathrm{~m}$ dan tinggi 2,4 $\mathrm{m}$ dengan kapasitas pengeringan sebesar $800 \mathrm{~kg}$. Suhu tertinggi dalam ruang pengering sebesar 
51,9 oC dengan intensitas matahari sebesar $990 \mathrm{~W} / \mathrm{m}^{2}$. Waktu pengeringan kopi dengan cara natural selama 7 hari sedangkan untuk cara honey selama 4 hari, lebih cepat 2 hari dibandingkan penjemuran dengan matahari langsung dan kopi yang dihasilkan lebih higeinis.

\section{UCAPAN TERIMAKASIH}

Terima kasih kepada Direktorat Riset dan Pengabdian Masyarakat. Kementrian Riset, Teknologi dan Pendidikan. Nomor SPPK : 198/SP2H/PPM/DPRM/2019

\section{DAFTAR PUSTAKA}

AH Tambunan, K Abdullah, B Nababan . 2006. Analisis Eksergi Penyimpanan Panas untuk Sistem Pengeringan Berenergi Surya. Jurnal Keteknikan Pertanian 20 (3)

A Kamaruddin. 2007. Energi terbarukan untuk mendukung pembangunan pertanian dan perdesaan. Renewable energy in supporting agricultural rural area development. IPB Press

A.S. Uyun, K. Abdullah, A. Winata. 2011. "Konsep Rancangan Energi di Dusun Tangsi Jaya, Gunung Halu, Bandung Barat sebagai Model Desa Mandiri Energi (DME). Seminar Penelitian Unsada, 13 Maret 2011. Universitas Darma Persada. Jakarta

Jyoti Singh and Pankaj Verma. 2015. Fabrication of Hybrid Solar Dryer". International

Journal of Scientific and Research Publication, volume 5, Issue 6, June 2015.

Gunasekaran, K., Shanmugam, V. dan Suresh, P. 2012. Modeling and analyticalexperimental study of hybrid solar dryer integrated with biomass dryer for drying coleus forskohlii stems 2012. IACSIT Coimbatore Conferences IPCSIT 28: 28-32.

Nuriana, W., N. Anisa dan Martana. 2013. Karakteristik biobriket kulit durian sebagai bahan bakar alternatif terbarukan. Jurnal Teknologi Industri Pertanian. Vol. 23 No. 1: 70-76.

Supriyanto dan Merry. 2010. Studi kasus energi alternatif briket sampah lingkungan kampus

Priyanto, S., 2017. Rancang Bangun Drum Oven Mesin Pengering Limbah Ikan untuk Pakan Ternak. Jurnal Kajian Teknik Mesin, 2(2), pp.128-132.

Polban bandung. Prosiding Seminar Nasional Teknik Kimia “Kejuangan”.Yogyakarta.Hal.1-9.

Priyanto, S., Nofendri, Y. and Fudholi, A., 2019. Performanceof slow pyrolysis open bach low-temperature reactor for agriculture residues. International Journal of Engineering and Advanced Technology, 8(5), pp.2088-2091.

Widyotomo, Sukrisno \& Mulato Sri. 2015 Penentuan Karakteristik Pengeringan Kopi Robusta Lapis Tebal. Buletin Ilmiah INSTIPER Vol 12 No 1, pp 15-37, 2005.

Yefri Chan, Asyari Darius, 2018 .Analisis Pengeringan Sohun Dengan Mesin Pengering Hybrid Tipe Konveyor Otomatis. Flywheel. Jurnal Teknik Mesin Untirta Vol. IV, No. 2, Oktober 2018, hal. $39-42$.

Yefri Chan, Yendi Esye. 2016. Rancang Bangun Mesin Pengering Hybrid Tipe Konveyor Otomatis. Prosiding Seminar Nasional Tahunan Teknik Mesin (SNTTM) XV. ITB Bandung 2016. Hal 43-47. 